\title{
The design of HV Source for Electron Beam Welder Based on Computer Technology
}

\author{
Hanmin Ye \\ Guilin University of Technology \\ Guilin, Guangxi, China
}

\author{
Xiaofei Liu \\ Guilin University of Technology \\ Guilin, Guangxi, China \\ xiaofeiliu0707@126.com
}

\begin{abstract}
This paper mainly introduces the working principle of $\mathrm{HV}$ (high voltage) source with inverter for electron beam welder. By using the computer to control HV source for electron beam welder and adopting IGBT as the inverter component, to achieve efficient miniaturization of the power source. Meanwhile the use of computer program control can ensure the power source intelligently and meet the requirements of electron beam welding. The test results show that the designed HV source can realize the expectation aims and meet requirements of the welding technology for electron beam welder.
\end{abstract}

Keywords- computer control; electron beam welder; HV source; PWM; inverter

\section{INTRODUCTION}

With the rapid development of computer, electronic and power electronic technology, new components and advanced technology have been successfully applied in electron beam welder as well as the design and manufacture of high voltage have been improved, such as using closed loop control which high voltage could be controlled automatically, the performance of high voltage and welding quality also could be significantly improved. Meanwhile, the application of electronic has contributed to the development of electron beam welder, for instance, the new power electron device, digital control technique and automatic can make the welder foolproof and reliable. Nowadays the adoption of computer control by the large electron beam welder and the production lines of electron beam technique can realize intelligence operation and control. The minimal welder which controlled by PLC can be controlled easily, where PLC is of antiinterference and control ability.

\section{THE MAIN CIRCUIT OF HV SOURCE}

The schematic diagram and main circuit of HV source are separately shown in Fig.1 and Fig.2.

\section{A. EMC Filter Circuit}

EMC filter circuit adds to the interior of circuit by the power line filter which is composed of $\mathrm{L}$ and $\mathrm{C}$. It includes normal rejection and common mode rejection circuit that can suppress normal and common mode noises effectively.

\section{B. Controlled Rectifier Circuit}

Controlled rectifier circuit composes of integrated intelligent voltage controlled module wherein filtering circuit is comprised of L1 and C3 that would be obtain steady DC voltage. Meanwhile Rc and Rd, constitute a precise feedback sample circuit that ensure the output voltage stability under the control circuit.

\section{IGBT Inverter}

The inverter consists of half-bridge capacitor, IGBT, high-voltage transformer and protection component. Inversion of the square voltage boosts into $40 \mathrm{kV}$ high frequency $\mathrm{AC}$ voltage by $\mathrm{HV}$ transformer $\mathrm{T}$. In order to eliminate the interference signal, we have adopted dual shielding which add double-shield between high tension coil and low tension coil. In Fig.2, the first shielding is at earth potential, the second connects with sampling resistor of the beam current. Consists of VL11, R9, C9, VL21, R19 and RC19, peak absorbing circuit can ensure the safety of IGBT.

\section{HV Rectifying Circuit}

HV rectifying circuit comprises high-frequency and high- 

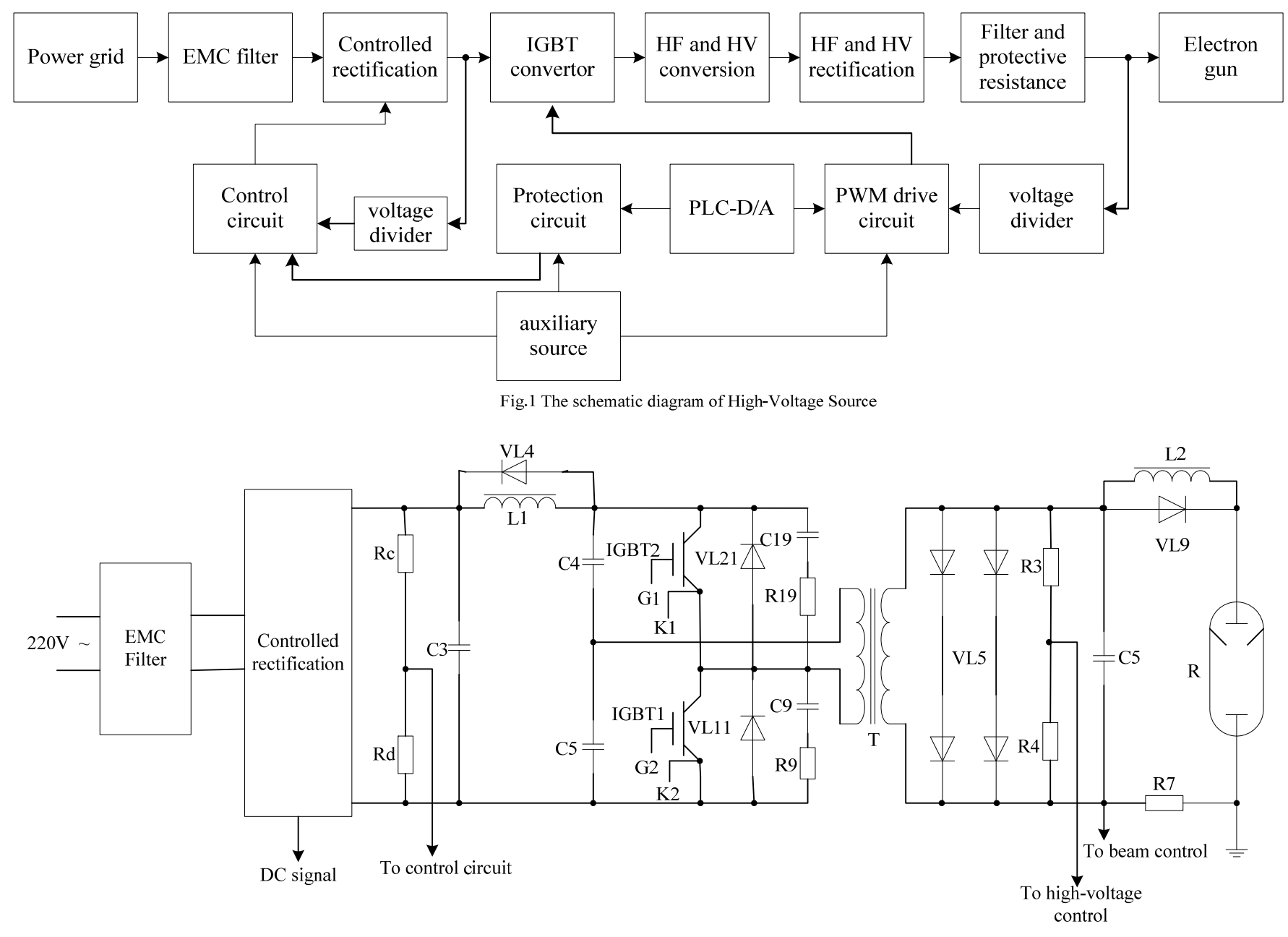

Fig.2 The main circuit of High-Voltage Source

tension silicon stack, high-tension filter capacitor, protective resistance and sampling circuit wherein the filter capacitor uses high-tension polystyrene film capacitor which has less $\tan \delta$ and high frequency, to make the power output better. The limiting and protective resistor have a stable thermal property, less self inductance, more discharge capacity, more withstand over-voltage and anti-force capacity. Be made up of precise non-inductive wire-wound resistor, the potentiometer can obtain the sampling signals and erect shielded electrode on top of the sampling circuit, to ensure the sampling voltage stability.

\section{PRINCIPLES OF THE HV SOURCE}

\section{A. HV Control System}

The control system of HV source for electron beam welder is mainly composed of a main circuit, control circuit and PLC control software as the schematic diagram is shown in Fig3.

Consist of EMC filter, DC thyristor booster, half-bridge converter, high-frequency transformer, high-frequency, high-voltage rectifier filter, the measurement of $\mathrm{HV}$ and beam current and sampling, the main circuit which working principle is that the line voltage rectifies adjustable DC voltage by EMC filter and DC thyristor booster, as the power source of the inverter, what turns into $20 \mathrm{kHz}$ squarewave voltage by means of the half-bridge inverter and outputs DC high voltage which has less pulse, to provide high-voltage accelerating field for electron gun.

PWM circuit, high-voltage feedback and PID regulator comprise the control circuit. PWM circuit is used for controlling the soft start of the inverter, providing $40 \mathrm{kHz}$ square wave pulse, isolating drive and over-current protection. HV source include precise $\mathrm{HV}$ meter, $\mathrm{HV}$ isolating circuit and D/A converter which turn high-voltage DC signal into low-voltage signal and send to PLC by D/A converter as the feedback of PID. Consist of A/D converter, data setting and circumscribed analog circuit, the given have two work-mode. Analog signal given by the analog potentiometer would turn into digital signal by $\mathrm{A} / \mathrm{D}$ as a given of PID while manually. When used automatically, the set value would be set by PLC directly and PID could output ramp function according to the gradient program in PLC as soft reset of HV source. PID comprise PLC and D/A which 
operation is finished by PID command, including pulse delay, proportionality constant, differentiating time constant, integral constant and filter constant. After PID operation, the digital signal would turn into analog signal by $\mathrm{D} / \mathrm{A}$ as the control voltage, to control the output of DC booster. The principle is that the control voltage would be raised by the feedback and PID operation and the output voltage of variable voltage module, the inverter, $\mathrm{HV}$ transformer all have been improved, the improvement of DC output voltage can stabilize and adjust DC high voltage.

\section{B. PWM and Driving Circuit}

In Fig.3, TL494 modulate PWM signal and the amplifier of TL494 connects current signal as over-current protection. After regulating, the feedback and given signal would be modulated two complementary PWM pulse by TL494. The working process of the control circuit is that all signals would be input into TL494 by PI regulator and output PWM pulse which duty ratio determined by the output signals of PI regulator. PWM pulse which has a duty ratio would drive
IGBT by EXB840 to ensure adjustable and steady output voltage of the transformer.

\section{Protection Circuit}

The internal of HV source would cause over-current or over-voltage which can damage HV source or IGBT during the HV source works, so we could adopt protective circuit to ensure the power source safely. The power source has overvoltage protection, gradient ascend and descent circuit and over-current protection. The EXB840 circuit can detect over-current protection itself where the 6 pin of IGBT would detect over-current signal and turn out the output pulse directly to cut off IGBT when IGBT flows more current. The second-level protection which use the 15 and 16 pin of the amplifier in TL494 to connect with current isolating sensor, TL 494 would turn out the output pulse that realize the cut-off of IGBT when the current exceeds the setting value. The third-level protection is the over-current protection of beam current in the side of $\mathrm{HV}$

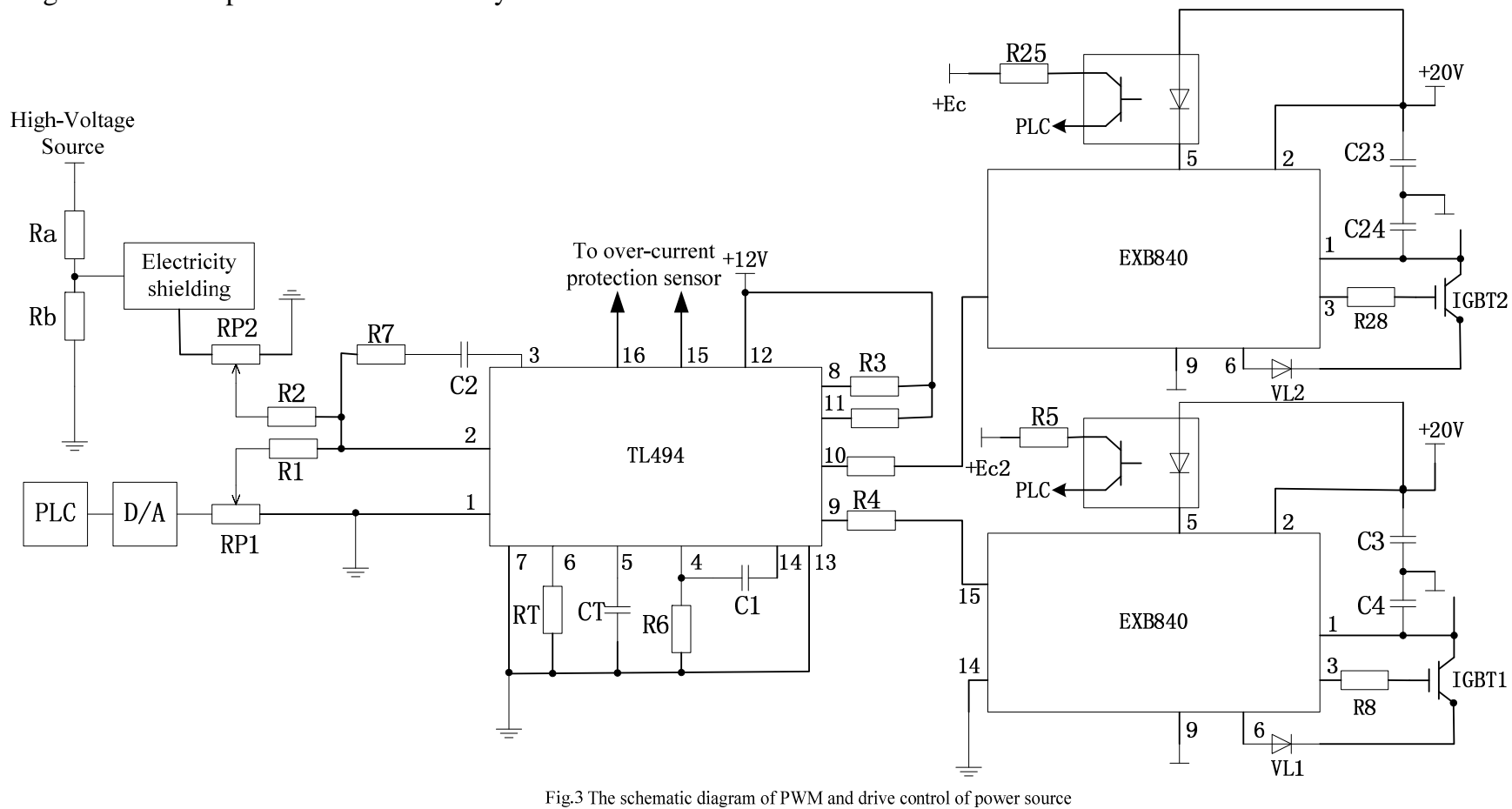

source where the sampling signal of beam current could be feedback to the control circuit which would send overcurrent signal to PLC while occurs over-current, PLC send signal to cut the main circuit, enabling the over-current protection. The over-voltage protection circuit can protect the power source effectively and erect limiting and protective resistor in the internal of $\mathrm{HV}$ source which can limit over-current and over-voltage effectively. In order to overcome a surge of HV source, we would set a ramp function of soft reset in PLC as the given of PI regulator by $\mathrm{D} / \mathrm{A}$ to ensure soft reset of HV source.

\section{TEST RESUltS}

The test results of HV source are as follows.

-No-Load Test. According to the setting boosted speed, we have added on $100 \mathrm{kV}$ high voltage to the source per one minute that the control system can work regularly;

-Short-Circuit Test. The secondary winding of highvoltage transformer shorts out with the primary winding through the control system of high source makes the secondary winding attain the rated current, the short-circuit impedance is $17 \%$ that match the requirement of highvoltage rectifier; 
-Welding Test. Beam current100mA, welding time 5 minute, output voltage $60 \mathrm{kV}$, ripple coefficient $0.79 \%$, stability 10-4.

-Welding Test of Full Power. Beam current is $167 \mathrm{~mA}$, the power source and control system can work regularly when the ripple coefficient of beam current is $0.87 \%$;

-Power Source Efficiency Test. Beam current $167 \mathrm{~mA}$,high voltage $60 \mathrm{kV}$, output power $10 \mathrm{~kW}$, input power $12.6 \mathrm{~kW}$, efficiency $79.3 \%$.

\section{ENDING}

Using the computer to control $\mathrm{HV}$ for electron beam welder, it is beneficial to realize miniaturization in the whole device, especially in favor of the portable electron beam welder, which results in improved availability and welding procedure of the device and performance of beam spot. Owing to the improvement on reliability and efficiency of $\mathrm{HV}$, middle-power welder which use the designed $\mathrm{HV}$ source $(3 \sim 15 \mathrm{~kW})$ is worth popularizing and applying. Meanwhile, effective measures have been taken to control the over-current and over-voltage protection of IGBT and ensure EMC electromagnetic compatibility, where ensure the requirements of electron beam welder.

\section{REFERENCES}

[1] Hanmin Ye, "Electron Beam Technology and Its Application", Applicable Technology Market, China, vol. 01, pp. 41-43, January 2000.

[2] Hanmin Ye, "Application of PLC Technology in the Vacuum Electron Beam Welder”, Vacuum, China, vol. 01, pp. 50-52, January 2000.

[3] Hanmin Ye, “Application of PLC in electronic beam welder," Electric Welding Machine, China, vol. 30, pp. 10-13, June 2000.

[4] Hanmin Ye,"Design of PLC Control System of High Voltage Source for Electron Beam Welder”, Power Supply Technologies and Applications, China, vol. 6, pp. 47-50, August 2003.

[5] Shaoxiang Zhu, The Principle and Application of Programmable Controller, Shanghai:Shanghai Jiao Tong University Press, 1998. 